\title{
History of X-ray Research in Colonial India*
}

\author{
S C Roy**
}

(Received 22 April 2018; revised 14 May 2018)

\begin{abstract}
$\mathrm{X}$-ray research in India is as old as the discovery of X-rays. The history of X-ray research in colonial India is fascinating, which started with the procurement of X-ray tube by Mahendralal Sircar within six months of the discovery of X-rays at the Indian Association for the Cultivation of Science (IACS). An X-ray machine was built by Sir Jagadish Chandra Bose at Presidency College (now Presidency University), Kolkata within two years of the discovery. The first application of X-rays for clinical purpose, although in private capacity, was done independently by Dr. Sircar and Sir J C Bose. Within another twenty five years, C V Raman initiated X-ray scattering studies at the IACS after his return from England in 1921, which proliferated to all parts of India and acted as the foundation stone of modern X-ray research in India. The paper has identified some areas which require further investigations.
\end{abstract}

Key words: IACS, J C Bose, Mahendralal Sircar, X-rays.

\section{X-Ray Discovery and ITS Impact in India}

Wilhelm Conrad Roentgen (1845-1923) has been credited with the discovery of X-rays and was awarded the first Nobel Prize in Physics in 1901 for his discovery. Research on discharge of gases was fashionable in the late nineteenth century. Roentgen's discovery is known to be the result of an accident while he was experimenting with a discharge tube. First oral presentation of the discovery of X-rays was made by Roentgen on January 23, 1896 and it was Kolliker, Chairman of the meeting, who proposed that this ray should be called Roentgen rays. November 8, 1895 was accepted as the date of discovery of X-rays (Grigg, 1965).

There are evidences of X-rays being produced experimentally even before Roentgen's date in 1895. This is not surprising because the basic physical process of generation of X-rays is the passage of electricity through gases (discharge) and, therefore, anyone involved in studying discharge of gases was unknowingly producing X-rays. As has been reported (Roy, 2017), the first recorded evidence to produce Roentgen rays was about 110 years before Roentgen by William Morgan (1750-1833), published in the Philosophical Transactions (Morgan, 1784).

It is interesting to note that when vigorous research on discharge tubes and electric rays (as it was called at that time) was in progress in Europe, Father Lafont (1837-1908) of St. Xavier's College, Calcutta (Fig. 1) brought a Crooke's discharge tube from Europe and delivered a lecture titled 'Crookes on Radiant Energy' in the Science Association in 1880 (Biswas, 2000). It also reported that Lord Lytton, the then Viceroy of India, invited Mahendra Lal Sircar (1833-1904), founder of IACS, to demonstrate the actions of Crookes tube and 'two ancient European professors of science' who did not believe in the bombardment of ions argued against Sircar (Roy, 2017).

\footnotetext{
* This work was sponsored by the History of Science Division of Indian National Science Academy

** Indian Science News Association, 92 Acharya Prafulla Chandra Road, Kolkata 700009, Email: suprakash.roy@gmail.com
} 


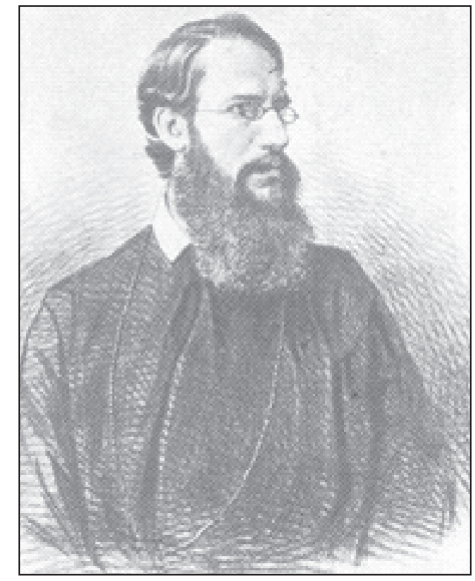

Fig. 1. Father Lafont

\section{First X-RAY USE IN INDIA}

It is not known exactly when and how the news of X-ray discovery reached Calcutta (now Kolkata), but it is fascinating to note that it had produced a huge interest among the science lovers of colonial India. Within a few months of the discovery of X-rays, Mahendralal Sircar (MLS) ordered a Roentgen tube from Ducretet Company in Europe and received it in June 1896. As noted in his diary dated $11^{\text {th }}$ June 1896 ,

The cases ( 3 in number) from Ducretet containing apparatus for experimenting with Roentgen Rays were brought from the Customs House to the Association today. With Amrita ${ }^{1}$ opened them and found that they have omitted to send the Flourescent Screen. The cathode disc was slightly bent. The cells were too big (Biswas, 2001).

The first experiment using X-rays in India was carried out by MLS (Fig.2) on 20 $0^{\text {th }}$ June 1896 by taking the photograph of a hand using the procured Roentgen's apparatus and it was noted in diary that the picture was not good probably due to overexposure. He repeated his experiment to obtain a better photograph and became successful on $23^{\text {rd }}$ June. As noted in his diary:

After visiting the patient at Maniktala, came to the Association and performed experiments on the Xrays, The first was a failure, evidently from overexposure. The second (frog) was particularly

${ }^{1}$ Amrita Lal is the son of Mahendralal Sircar

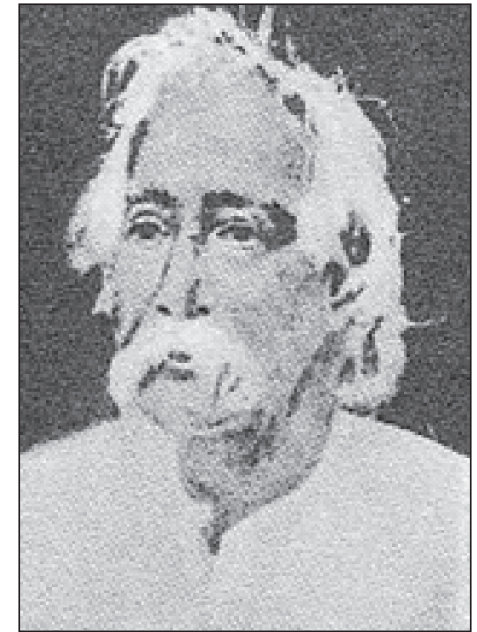

Fig. 2. Mahendralal Sircar

successful. The third (a coin on a plank) was very successful.

Therefore, according to his diary, the first successful X-ray photograph was produced in India on $23^{\text {rd }}$ June 1896 in Calcutta by MLS (Roy, 2015).

Being successful in his experiments with X-rays, Sircar delivered a one and half hour lecture on 'New Photography with X-rays of Roentgen' on $3^{\text {rd }}$ July at the Association before an audience of more than 300 persons. The Proceedings of the Twentieth Annual IACS meeting held on 11 September 1897 recorded 'The Association had thus the honour of being the first to place this remarkable discovery before the Indian public'. Experiments with X-rays were continued at the IACS by Amrita Lal Sircar under the guidance of MLS with blocks of wood and books of different thickness, with sheets of iron, tin foil and zinc foil as has been recorded in the diary of $13^{\text {th }}$ December 1899 (Biswas, 2001). This was the beginning of $\mathrm{X}$-ray research in India after the discovery of Xrays and thus IACS has the distinction of initiating $\mathrm{X}$-ray research in India.

It will be pertinent here to mention that Pradyot Kumar Tagore, son of Sir Jatindramohan Tagore, who was trained in England on photography, specially X-ray photography, teamed 
up with Father Lafont to take an excellent photograph of the right hand of Earl of Elgin, the then Viceroy of India, wearing rings (Ghosh, 1991). The picture was published in the Journal of Photographic Society of India in 1897.

\section{Jagadis Chandra Bose and hIS X-RAY Apparatus}

Acharya Jagadis Chandra Bose (18581937) (Fig.3) was the first person in India who built an improved Roentgen's apparatus on his return from England in 1897. The exact date of his building the apparatus is not known but it appears to have been built sometime around 1897 1898. Acharya Bose visited Europe in 1896 at a time when the excitement of the discovery of Roentgen rays in Europe was at its peak. It is possible that Jagadis Chandra, being a physicist and an exceptional experimentalist, was attracted to this discovery and studied in detail about the production of Roentgen rays. Jagadis Chandra Bose returned to India in April 1897 and started building the apparatus (Roy, 2017).

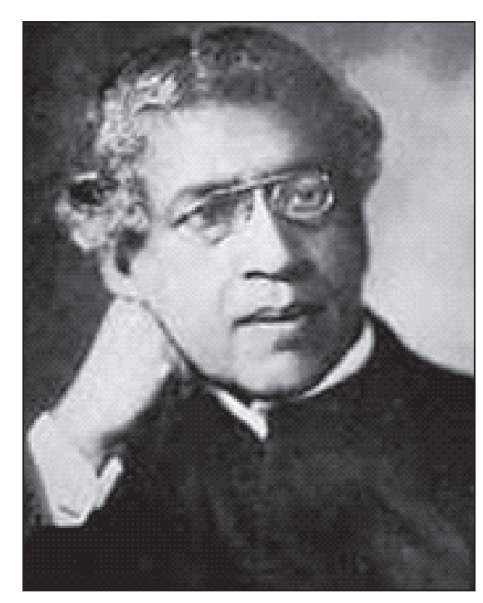

Fig. 3. Jagadis Chandra Bose

D M Bose, his nephew and former Director of Bose Institute, remarked in one of his articles that after 'reading a newspaper account of Roentgen's discovery' he built an X-ray apparatus in Presidency College, Calcutta (Bose, 1949).
We found the first mention of his X-ray apparatus in a letter written to Rabindranath Tagore in February 1898 (Roy, 2015). It was reported in the magazine Prabāsī that 'Shri Jagadindu Ray who lived in Serampore was an assistant of Jagadis Chandra Bose' and 'the machine was built at Presidency College by Jagadindubabu under the guidance of Jagadis Chandra Bose' (Chattopadhyay, 1935).

Unfortunately, neither the apparatus nor any sketch of his apparatus is available either at Presidency College or at Bose Institute to understand the mechanism of the apparatus. Fortunately enough, we have been able to find a Press Report (1898) published in the $5^{\text {th }}$ May 1898 edition of the Amrita Bazar Patrika under the title 'Professor Bose and the New Light' about Jagadis Chandra's X-ray apparatus and its demonstration. It reported
We were shown a photograph of human palm taken by the Professor with the new light, and the ghastly sight will long be vividly imprinted in our memory, for there, in the photograph, instead of the ordinary fleshy palm is seen depicted a long range of bones presenting a skeleton like appearance". Professor Bose also demonstrated some other experiments like "a leather money bag, containing a rupee and a knife was interposed between the fluorescent screen on when the images are projected and the vacuum tube through which sparks were passing. No sooner was the leather money bag interposed, than there appeared on the screen an image of the rupee and knife reproduced with the astounding fidelity.

The Press Report (1898) described the improvement that Jagadis Chandra had made in his apparatus over that of Roentgen. Roentgen connected the secondary of the Ruhmkorff's coil as a source of transient high voltage to the discharge tube in discharging the gas. A high voltage pulse is generated in the secondary coil by electromagnetic induction every time a DC supply in the primary is interrupted by a mechanical contact and produces X-rays. The news report mentioned 'he has managed to get 
far better results by connecting the induction coil with a Tesla Transformer and then allowing the sparks to pass through the vacuum tube. The simple function of the piece of apparatus known as the Tesla Transformer when connected with a Ruhmkorff's coil is to increase its power enormously and hence it is evident the new arrangement cannot but yield excellent results.' Based on this information we have produced a schematic diagram of the apparatus he had probably used (Fig.4). The paper reported that Jagadis Chandra intended to procure another huge Tesla Transformer from Europe, which will be thousand times more powerful than the one in his possession.

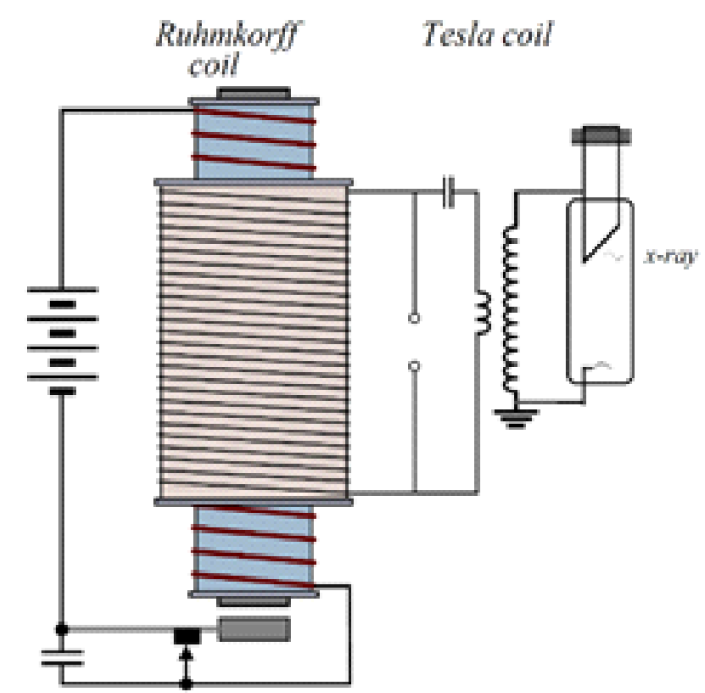

Fig. 4. Schematic diagram of the high voltage source J C Bose probably used remark:

The report concluded with the following

He would join it with the Dynamo Electric Machine in the Presidency College and with this splendid apparatus, (which would be at least 5,000 times more powerful than the present arrangement) in the hands of so skillful an experimenter, we anticipate brilliant achievements in a hitherto dark and unexplained region of science. Even with the poor means in his hands he has got excellent results, results which would be creditable to the experimental skill of any scientist.
It is not clear where Jagadis Chandra got the X-ray tube from. Was it the same X-ray tube that was imported by MLS to which the improved high voltage system was connected? Or did he borrow the discharge tube from his teacher Father Lafont (Roy, 2015)? This requires further investigation because the diary of MLS revealed some startling information and there are enough reasons to investigate further to find out the truth. The diary dated $6^{\text {th }}$ March 1899 recorded the following
Went in the evening to see the case of cystic tumor in Bechuram Chatterjee Street. Suresh's (Dr. Suresh Prasad Adhikari) apparatus for photographing Roentgen Rays did not act well. He said it has been spoiled by J C Bose (Biswas, 2000).

While the Press Report of $5^{\text {th }}$ May 1898 did not give any detailed description of the photographic process used by Jagadis Chandra Bose, it was mentioned that the photographic process was a tedious one and reported that 'Professor is completing an arrangement by which an image may be projected on a screen and thus viewed directly by a number of curious spectators'. Jagadis Chandra, being a scientist of excellent calibre, did not stop there by just taking photographs of different objects but started investigating the interaction of $\mathrm{X}$-rays with various bodies.

Jagadis Chandra used a barium platinocyanide screen to record X-ray photograph as was done by Roentgen. He created the screen in his laboratory at Presidency College by assigning a young research assistant Nagendra Chandra Nag 'to prepare barium platinocyanide screens with which he took X-ray photographs of different objects like a human hand, coins enclosed in a purse; some of them were reproduced in a juvenile monthly 'Mukul' for which he often used to write popular articles on scientific topics in Bengali' (Bose, 1949).

The Amrita Bazar Patrika (Press Report 1898) also reported that on the suggestion of 
Professor Bhaduri of the Chemical Laboratory, Jagadis Chandra succeeded in finding another substance, Potassium Platinocyanide, 'which is far more easily obtained than the corresponding Barium compound, is equally effective and hence may be substituted for Barium Platinocyanide in these researches.' The report ended with 'The researches, however, are not yet completed and we await the result with interest.' Nothing is known about his further research on X-rays after that, one of the reasons being that Jagadis Chandra himself became more interested later in bio physics and left mainstream research in physics.

It is interesting to note that although use of X-rays in India was started immediately after a few months of X-ray discovery by importing Xray machine from abroad and an X-ray machine was fabricated in the laboratory within about two years of the discovery, commercial production of indigenous machines in India took many more years. It appears from the book published on the history of X-rays entitled 'The Trail of the Invisible Light' (Grigg, 1965) that the first X-ray machine was built in India by Shri Bibhu Bilas Bhowmik, FNA of Calcutta a few years before independence (Roy, 2017).

\section{Medical Uses of X-Rays}

According to available literature, the evidence of first clinical uses of X-rays in India, at least in an informal setting, was started by Jagadis Chandra Bose in 1898. In a letter (Sen, 1994) written possibly in February 1898 to Rabindranath Tagore, Jagadis Chandra wrote

if possible please come to the Presidency College at 8 in the morning. I have to examine a patient using Roentgen kol (machine) - he has broken his back. You may feel that this is not as dangerous as malaria which is prevalent in this country. I too had mentioned this but could not avoid Dr. Nilratan Sircar's request. In case you can not go to the college, come directly to no 85 at 9 . I will be back by then.
This is the first recorded evidence of medical uses of X-rays in India.

In another article published in Prabāsi, Jogendra Kumar Chattopadhyay (1935) reported that Professor Bose, Doctor Captain Chatterjee and Satyendranath Thakur were looking at bones of his broken hand with great interest. He mentioned 'Satyendrababu told to his friend in English that this is probably the first picture of broken hand taken using X-rays in Calcutta. There was no Xray machine available then in Calcutta.' There is no doubt that Jagadis Chandra and Mahendralal Sircar were the persons who started using X-rays for medical purpose around 1898.

The history of application of X-rays by professionals for clinical purpose in India is not very clearly known. As reported (Bose, 2010), Dr. Kartick Bose (1873-1955), an eminent doctor, medical scholar and industrialist was "the first clinician in India to start clinical and X-ray laboratories'.

Installation of first X-ray machine in hospitals for public use is full of claims, counterclaims and conflicting reports so much so that it is very difficult to arrive at a definite conclusion. It has been reported by K P Mody (1956) in his editorial published in the Indian Journal of Radiology \& Imaging that 'the first X-ray machine was imported by a chemist in 1902 into India; that was only 7 years after the discovery'. Madras Medical College website (www.mmc.ac.in.) claimed that the 'first X-ray outfit was obtained for the general hospital in the year 1900 almost five years after the discovery of X-rays, the first in South East Asia'. This might be true considering that it is a very old medical institution first started as a Government General Hospital on $16^{\text {th }}$ November 1664 to treat sick soldiers of the East India Company (Fig.5).

Although the authenticated date of installation of X-ray machine in Calcutta Medical College is not known, we can infer from other 


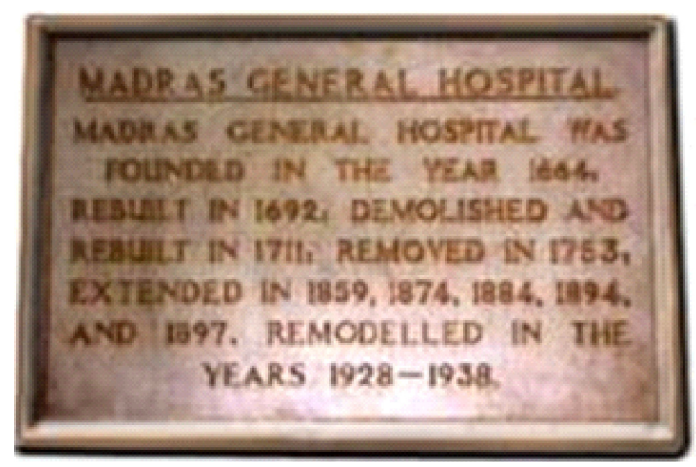

Fig. 5. Madras General Hospital tablet showing its status during 1664-1938

evidences that X-ray machine was available in Calcutta Medical College at the beginning of twentieth century. Successful treatment of leukemia using X-rays was reported (Chatterjee, 1907) in Calcutta Medical Journal within five years of the first ever treatment of leukemia using X-rays reported in a paper published in the Journal of the American Medical Association in 1902.

Assam Medical College (which was earlier known as Berry-White Medical School claimed in its website (https://en.wikipedia.org/wiki/ Assam_Medical_College) that 'the college imported two X-ray machines from England in 1910, which were the first in India and opened the country's first radiology department'. Similarly, Sharmila Das (2013) reported in a publication 'since the first X-ray machine in India in Lady Hardinge Hospital, New Delhi in 1918, Indian Radiology has walked through many evolving phases'. We found a similar statement in the website of Indian Radiological Association that first X-ray machine was installed at Lady Hardinge Hospital in 1918 and a radiology department was established in 1923. It also stated that first deep X-ray therapy was started in New Delhi in 1935. According to our present findings, none of the above reporting is correct. More investigations are required in this direction.

We found an official record in a book published on the occasion of 175 years of Calcutta Medical College (2009) that the Department of
Radiotherapy in Calcutta Medical College was inaugurated by $\mathrm{H} \mathrm{E}$ the Countess of Minto on $25^{\text {th }}$ January 1910. It was integrated with the existing Department of Radiology and remained like that till 1948. The Centenary Volume of Medical College (1935) reported that H.E. Lady Reading paid a donation of Rs. 9719/- in 1926 for the Deep Therapy Plant of the X-ray Department.

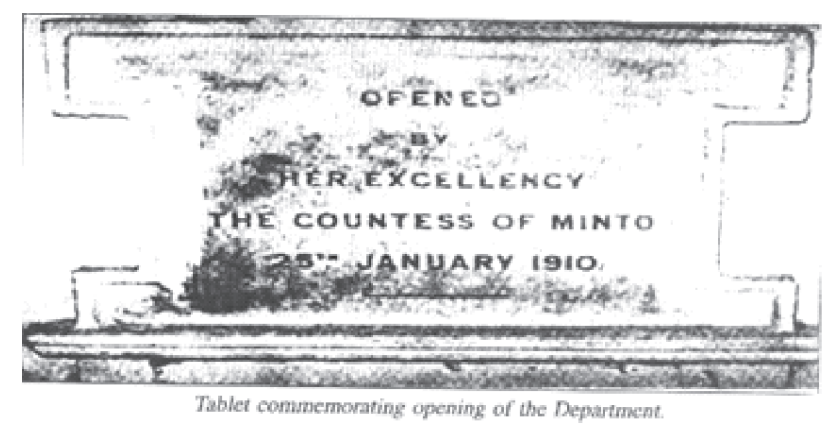

Fig. 6. Tablet showing the Inauguration of the Dept. of Radiotherapy

The Radiology Department of the Campbell Medical School, Calcutta (now known as Nilratan Sircar Medical College) was started in 1923 with one consultant as an Honorary Radiologist and Head of Department (Mukherjee, 1973). The first X-ray machine was a French-make $30 \mathrm{~mA}$, which used to be called Gaiffe X-ray plant. It has been reported that in earlier machines people were more concerned about the electrical hazards of high tension cables than the radiation hazards because electrical shield of cables were not completely shock-proof.

\section{IACS: The Nucleus of X-RAY RESEARCH IN INDIA}

Excitement of using X-rays in medical science waned with time and was replaced by Xray research in physical sciences. C V Raman and his students at the IACS started investigations on optical anisotropy of molecules from scattering of light. C V Raman on his return to India in 1921 after his England trip, initiated research on the scattering of X-rays by liquids. Raman and 


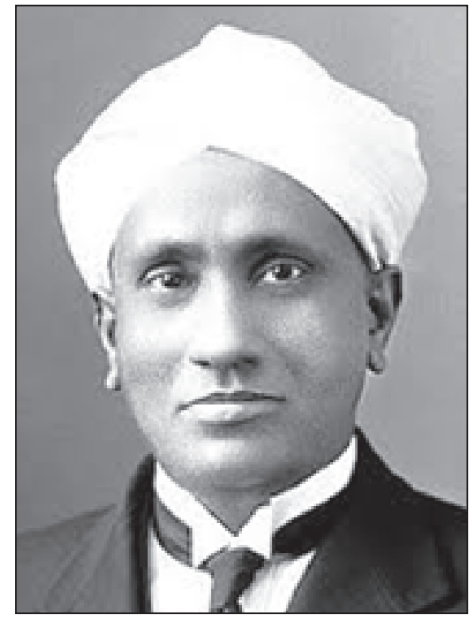

Fig. 7. CV Raman

Ramanathan (1923) extended the optical theory of scattering to X-ray diffraction by liquids. This field of research was continued in this laboratory by Sogani (1927) and others to compare the theory with experimental results. It became clear from these experiments that the shape of the molecules and the intermolecular forces had profound influence on the diffraction patterns. Krishnamurti (1930), another student of Raman initiated small angle X-ray scattering which enabled us to understand the size and distribution of the particles in a sample. This is reportedly the first small angle $\mathrm{X}$-ray scattering experiment (Chu, 2001) done in India

Bidhubhusan Ray, another student of Raman, made significant contribution to X-ray spectroscopy, although he remained unknown to most physicists until a book was published by Rajinder Singh (2017). Bidhubhushan Ray worked with Manne Siegbahn, a Nobel Laureate in Physics, at Uppsala and on his return to India established X-ray laboratory at Calcutta University. Satyendranath Bose who visited Europe during 1924-26 met de Broglie brothers and was attracted to X-ray crystal structure. His experience was utilized both at Dhaka University and later on at the Calcutta University where he took charge of the X-ray laboratory after the premature death of B B Ray and built an X-ray diffraction apparatus in the laboratory.

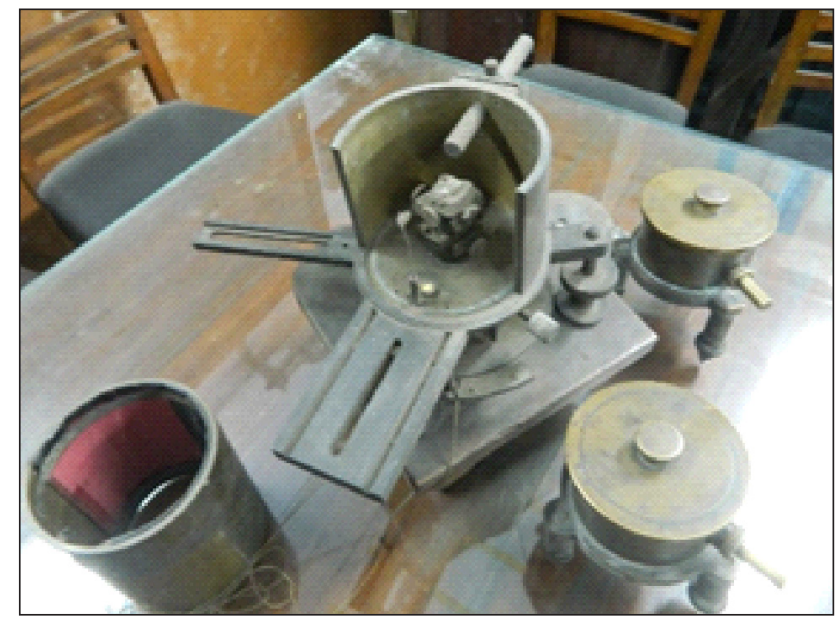

Fig. 8. X-ray Diffraction Apparatus built by SN Bose (Courtesy: Prof. Alok Mukherjee)

Around the same time, a new approach was proposed by Kedareswar Banerjee to the solution of crystallographic phase problem, which not only broke new ground beyond the 'trial and error' method of structure solution available at that time, but also heralded the extremely powerful direct methods of crystallography of the modern era (Banerjee, 1933). His further research on crystallography paved the way for a 'complete crystallography structure analysis' and for understanding statistical relationships in the amplitudes of diffracted waves. Contributions of Banerjee were followed by equally profound works by other researchers in India such as A R Verma, S Ramaseshan and G Ramachnadran (Mande, 2014).
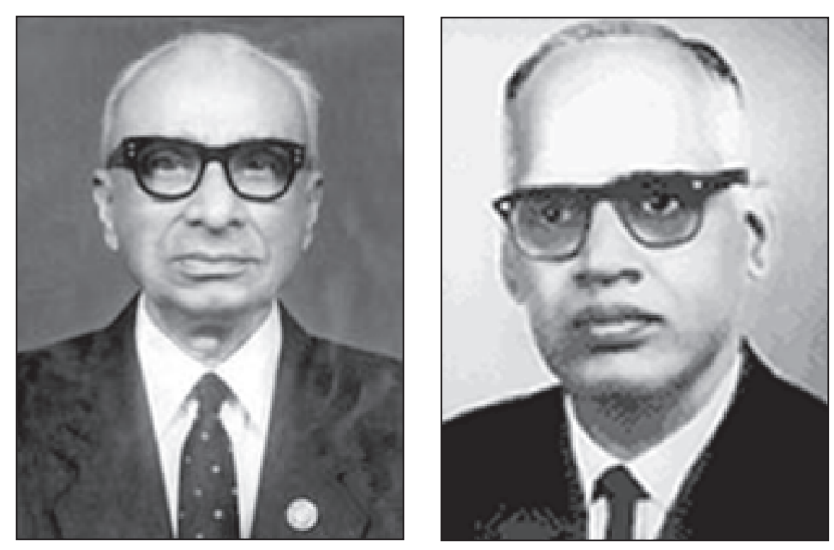

Fig. 9. Kedareswar Banerjee and G N Ramachandran 
Ramaseshan demonstrated that the phenomenon called anomalous scattering can be effectively used for determination of crystal structures. G N Ramachandran who with his students explored the structure of collagen by a combination of optical and X-ray methods, is quoted widely in textbooks as the Ramachandran Map.

\section{Conclusion}

$\mathrm{X}$-ray research was initiated in India immediately after the discovery of X-rays in 1895 by Mahendralal Sircar and Jagadis Chandra Bose and the first X-ray picture of broken bones was taken by J C Bose in 1898. Research in physical sciences using X-rays was started in India by C V Raman at the IACS. IACS acted as the nucleus of $\mathrm{X}$-ray research in India from where it proliferated to different laboratories like the Benares Hindu University, Allahabad University, Madras University, Indian Institute of Sciences, Bangalore etc.

\section{ACKNOWLEDGEMENT}

The author is grateful to Prof. Barun Kumar Chatterjee of Bose Institute, Dr. Rajinder Singh of University of Oldenburg, Germany, Dr. Gauri Roy, Formerly at the Indian Association for the Cultivation of Science and Prof. Alok Mukherjee of Jadavpur University and many others for providing important information, valuable discussions and comments. The author also thanks the authorities of Bose Institute and IACS for giving access to relevant documents.

\section{BiBLIOGRAPHY}

Banerjee, K. Determination of the signs of Fourier terms in complete crystal structure analysis, Proceedings of Royal Society, 141(1933): 188.

Biswas, Arun Kumar. Gleaning of the Past and the Science Movement (in the diaries of Drs. Mahendra Lal and Amritalal Sircar), The Asiatic Society, 2000.

Biswas, Arun Kumar. Father Lafont of St. Xavier's College, Calcutta and the Contemporary Science Move- ment, The Asiatic Society, March 2001, Appendix XXXV.

Bose, D M. The scientific activities of Acharya Jagadish Chandra Bose, Science and Culture, 14 (1949): 366.

Bose, Kaushik, Kartick Chandra Bose, Current Science, 98 (2010): 133.

Calcutta Medical College, 175 Years, Book published on the occasion of 175 years of Calcutta Medical College, Calcutta, 2009.

Centenary Volume of Calcutta Medical College, Calcutta Medical College, 1935.

Chatterjee, Gopal Chandra. A case of Leukaemia successfully treated with X-rays, Calcutta Medical Journal, 1 (1907): 269.

Chattopadhyay, Jogendra Kumar. Amar Dekha Loke (Person I saw), Prabāsī, Ashar (1342 beng), (1935): 380.

Chu, Benjamin and Hsiao, S. Small-angle X-ray scattering by polymers, Chemical Review, 101 (2001): 1727.

Das, Sharmila. Imaging the Next Revolution,http:// ehealth.eletsonline.com/2013/07/imaging-the-nextrevolution/ (July 2013).

Ghosh, Siddhartha. Kaler Sahar Kolkata, Ananda Publishers, Kolkata, 1991.

Grigg, E R N. The Trail of the Invisible Light, Charles C Thomas Publisher, 1965.

Krishnamurti, P. Studies in X-ray diffraction: The structures of Amorphous Carbon, Indian Journal of Physics, 5 (1930): 473.

Mande, Sekhar, Early developments in crystallography, Resonance, (2014): 1077.

Mody, K P. Editorial, The Indian Journal of Radiology and Imaging, (1956): 1

Morgan, William. Electrical experiments made to ascertain the non-conducting power of a perfect vacuum, Philosophical Transactions, LXXV (1784): 272.

Mukherjee, A K. Silver Jubilee of Nilratan Sircar Medical College and Centenary of Campbell Medical School Volume, 1973.

Professor Bose and the New Light, The Amrita Bazar Patrika (discontinued), $5^{\text {th }}$ May, 1898.

Ramachnadran, G and Kartha, G. Structure of collagen, Nature, 174 (1954): 269.

Raman, C V and Ramanathan, K R. The diffraction of Xrays in liquids, liquid mixtures, solutions, fluid crystals 
amorphous solids, Proc. Indian Association for the Cultivation of Science, Vol. VIII (1923): 127.

Roy, S C. Early years of X-ray research in India, Science and Culture, 81 (2015): 72.

Roy, S C. Discovery of X-rays and its Impact in India, Indian Journal of History of Science, 52.1 (2017): 66.

Sen, Dibakar. (Ed.) Patrābalī (Collection of letters of
Acharya Jagadis Chandra Bose written to Rabindranath Tagore), Bose Institute, Kolkata 1994, pp. 1-2 (letter no 19).

Singh, Rajinder. Bidhu Bhushan Ray-A Pioneer of X-ray Spectroscopy, Shaker Publishers, 2017.

Sogani, C M. X-ray diffraction in liquids, Indian Journal of Physics, 1(1927): 357. 